\title{
Prevalence of STHs (Soil transmitted helminthes) of school children in Sadar upazila, Mymensingh, Bangladesh.
}

\author{
${ }^{*}$ Rahman $\mathrm{MM}^{1}$, Hossain $\mathrm{MA}^{2}, \mathrm{Paul} \mathrm{SK}^{3}$, Ahmed S ${ }^{4}$, Alam $\mathrm{MM}^{5}$, Begum $\mathrm{Z}^{6}$ \\ Kabir MR ${ }^{7}$, Ansary $\mathrm{NB}^{8}$, Paul $\mathrm{AR}^{9}$
}

\begin{abstract}
Soil transmitted helminthes (STHs) infections are common throughout the tropics and subtropics and represents a major public health problem in developing countries. The rate of STHs infection found in the present study was very high in comparison to other countries of this Subcontinent, though they are taking antihelmintics every 6 months interval under Government National Health Program. The present study was carried out to see the Prevalence of STHs infection among the school children in Mymensingh, Bangladesh. A total of 500 stool samples from healthy individuals were collected during April, 2012 to February, 2013 from 20 schools comprising 10 rural and 10 urbans under Sadar upazila, Mymensingh, Bangladesh. The samples were examined in the department of Microbiology, Mymensingh Medical College using saline and iodine preparation microscopy and McMaster technique for the detection of ova of STHs.
\end{abstract}

The STHs prevalence irrespective of the age and sex of the individuals were $37.0 \%(185)$ out of 500 specimens where $68.0 \%(340 / 500)$ individuals were male represents the prevalence $38.0 \%$ $(129 / 340)$ and $32.0 \%(160 / 500)$ individuals were female represents the prevalence $35.0 \%(56 / 160)$. Majority of the cases belonged to the age group $>5-10$ years $50.2 \%(251 / 500)$ of the total, constituted the prevalence $20.2 \%(101 / 500)$ of the total population and $40.2 \%(101 / 251)$ of the individual age group. The distribution of different STHs with their prevalence in the study population where Ascaris lumbricoides (AL) was 63.8\% (118), Trichuris trichiura (TT) 37.3\% (69), Enterobius vermicularis (EV) $8.1 \%$ (15), Ancylostoma duodenale (AD) $7.5 \%(14)$, and mixed infection was $15.1 \%(28)$. The upper socio-economic class constituted $5.0 \%(25 / 500)$ of the total study population with the prevalence of $20.0 \%$ (5/25). The middle socio-economic class constituted $50.0 \%(250 / 500)$ of the total study population with the prevalence of $37.2 \%(93 / 250)$ and the lower socio-economic class constituted $45.0 \%(225 / 500)$ of the total study population with the prevalence of $38.6 \%$ (87/225). The urban population constituted $34.0 \%(170 / 500)$ of the total population representing the prevalence $31.2 \%(53 / 170)$ and rural population constituted $66.0 \%(330 / 500)$ of the total population representing the prevalence $40.0 \%(132 / 330)$.

In this study, STHs detection by McMaster method was satisfactory. Thereby, McMaster method could be adapted for rapid detection and quantification of STHs. Moreover, one more frequent administration of antihelmintics with close monitoring of drug administration may reduce the prevalence of STHs infection in Bangladesh.

CBMJ 2018 January: vol. 07 no. 01 P: 4-9

Key words: Soil transmitted helminthes, Prevalence, School Children.

1. Md Mahamudur Rahman. Assistant Professor, Department of Microbiology, Community Based Medical College Bangladesh, Mymensingh.

2. Md Akram Hossain. Professor of Microbiology (Ex), Mymensingh Medical College.

3. Shyamal Kumar Paul. Professor of Microbiology, Netrokona Medical College.

4. Salma Ahmed. AssociateProfessor of Microbiology, Mymensingh Medical College.

5. Md Murshed Alam. Professor of Microbiology, Community Based Medical College Bangladesh, Mymensingh.

6. Zohra Begum. Professor of Microbiology (CC), Community Based Medical College Bangladesh, Mymensingh.
7. Md Rashedul Kabir. Associate Professor (CC), Department of Microbiology, Community Based Medical College Bangladesh, Mymensingh.

8. Nahid Bintay Ansary. Professor of Physiology (CC), Community Based Medical College Bangladesh, Mymensingh.

9. Arup Ratan Paul. Associate Professor of Biochemistry, Community Based Medical College Bangladesh, Mymensingh.

Address of correspondence:

Email: drbulbulcbmcb@gmail.com Mobile: 01713116362 


\section{Introduction}

Infection by soil transmitted helminthes (STHs) is now being considered as an important public health concern, particularly in developing countries ${ }^{1}$. Typically, the helminthes involved are Ascaris lumbricoides $(A L)$, Trichuris trichiura (TT), Ancylostoma duodenale (AD), Strongyloides stercoralis (SS) and sometimes Enterobius vermicularis (EV). The three major STHs are AL (round worm) TT (whip worm) and AD (hook worm) are amongst the most widespread parasites worldwide ${ }^{1}$. An estimated 4.5 billion individuals are at risk of STHs infection and more than one billion individuals are thought to be infected, of whom 450 million suffer morbidity from their infections, the majority of who are children. An additional 44 million infected pregnant women suffer significant morbidity and mortality due to hook-worn associated anemia $^{2}$. Approximately 135,000 deaths occur per year, mainly due to infections with hookworms or round worms 3, 4,5,6. STHs transmission is enhanced by poor socioeconomic conditions, deficiencies in sanitary facilities, improper disposal of human faces, insufficient supplies of drinking water, poor personal hygiene, substandard housing and lack of education ${ }^{5}$. It causes malnutrition, anemia, growth and weight retardation as well as higher susceptibility to other infections. Hookworms cause blood loss and are one of the major contributors to iron deficiency anemia. It is an important health problem in our community ${ }^{2}$.

The greatest number of STHs infections occur in tropical and subtropical regions of Asia, especially China, India and Southeast Asia, as well as in Sub-Saharan Africa. Of the 1-2 billion STHs infections worldwide, approximately 300 million infections result in severe morbidity, which are associated with the heaviest worm burdens ${ }^{2,7}$. STHs study in Nigeria in 2009 shows the prevalence $47.6 \%{ }^{7}$. In 2012, STH study in China found the prevalence of $\mathrm{TT}, \mathrm{Al}, \mathrm{AD}$ respectively $81 \%, 44 \%$ and $6 \%$. In 2011, study in Srilanka found the prevalence of STHs $29 \%{ }^{8}$ and in 2004, study in India shows the prevalence of STHs infections for AL 91\%, TT $72 \%$ and AD 54\% ${ }^{9}$. In 1990 there was a study in Mymensingh, Bangladesh shows the prevalence of STHs infections was $72.2 \%{ }^{10}$. Recent study from Dhamrai, Dhaka (IEDCR-2011) showed the prevalence of STHs $32 \%$. So, the objective of this study was to evaluate an easier technique for diagnosis of soil transmitted helminthes, as well as to determine the prevalence of soil transmitted helminthes and infection intensity in the study population.

\section{Materials and Methods}

Following obtaining informed consent, school children between 4 and 18 years was recruited and asked to provide a recent stool sample of an interval of less than 4 hours to determine the prevalence of STHs infection. For the collection of specimens 20 different schools were selected randomly of which 10 from rural and 10 from urban area $^{11}$. Laboratory work was done in the Department of Microbiology MMC from the period April, 2012 to February, 2013. All the specimens were examined by normal saline \& iodine preparation microscopy for rapid detection of ova of helminthes. All fecal samples were processed using the McMaster egg counting technique (analytic sensitivity of $50 \mathrm{EPG}$ ) for the detection and the enumeration of infection intensity ${ }^{11-18}$.

\section{Result}

Among the 500-stool specimen, irrespective of age and sex of the individual prevalence were $37.0 \%(185 / 500)$ where $340(68.0 \%)$ individuals were male represents the prevalence $38.0 \%(129 / 340)$ and 160 $(32.0 \%)$ individuals were female represents the prevalence $35.0 \%(56 / 160)$.

Table 1. Male female ratio of the study population with their prevalence $(n=500)$

\begin{tabular}{|l|c|r|}
\hline & $\begin{array}{c}\text { Number of } \\
\text { Speciment (\%) }\end{array}$ & $\begin{array}{l}\text { Individual STHs } \\
\text { Prevalence (\%) }\end{array}$ \\
\hline Male & $340(68.0)$ & $129 / 340(38.0)$ \\
\hline Female & $160(32.0)$ & $56 / 160(35.0)$ \\
\hline Total & $\mathbf{5 0 0 ( 1 0 0 )}$ & $\mathbf{1 8 5 / 5 0 0 ( 3 7 . 0 )}$ \\
\hline
\end{tabular}

(Number in the parenthesis indicates percentage.) 
Majority of the cases belonged to the age group $>5-10$ years, $50.2 \%(251 / 500)$ of the total study population, where $33.6 \%$ cases were male and $16.6 \%$ cases were female and constituted the prevalence of STHs $20.2 \%(101 / 500)$ of the total population and $40.2 \%(101 / 251)$ of the individual age group (Table II). In the age group 1-5 years were $2.4 \%(12 / 500)$ of the total study population, where $1.6 \%$ cases were male and $0.8 \%$ cases were female and constituted the prevalence of STHs $0.8 \%(4 / 500)$ of the total population and $33.3 \%(4 / 12)$ of the individual age group. In the age group $>10$ 15 years were $34.2 \%(171 / 500)$ of the total study population, where $24.0 \%$ cases were male and $10.2 \%$ cases were female and constituted the prevalence of STHs $11.2 \%$ $(56 / 500)$ of the total population and $32.7 \%$
(56/171) of the individual age group. In the age group $>15-20$ years were $10.2 \%$ $(51 / 500)$ of the total study population, where $6.6 \%$ cases were male and $3.6 \%$ cases were female and constituted the prevalence of STHs $3.2 \%(16 / 500)$ of the total population and $31.4 \%(16 / 51)$ of the individual age group. In the age group $>20$ years were $3.0 \%(15 / 500)$ of the total study population, where $2.2 \%$ cases were male and $0.8 \%$ cases were female and constituted the prevalence of STHs $1.6 \%$ $(8 / 500)$ of the total population and $53.3 \%$ $(8 / 15)$ of the individual age group. In this study 15 cases were above 20 years of age. An Islamic school (madrasa) was selected for the study where some students were above 20 years of age; which is not uncommon in the perspective of our country

Table II. Detection of Soil transmitted helminthes (STHs) in the different age group of the study population $(\mathrm{n}=500)$.

\begin{tabular}{|l|c|c|c|c|c|}
\hline $\begin{array}{c}\text { Age group } \\
\text { (Years) }\end{array}$ & $\begin{array}{c}\text { Male } \\
(\%)\end{array}$ & $\begin{array}{c}\text { Female } \\
(\%)\end{array}$ & $\begin{array}{c}\text { Number of } \\
\text { Patients (\%) }\end{array}$ & $\begin{array}{c}\text { STHs } \\
\text { positive (\%) }\end{array}$ & $\begin{array}{c}\text { STHs prevalince for the } \\
\text { individual age group (\%) }\end{array}$ \\
\hline $1-5$ & $8(1.6)$ & $4(0.8)$ & $12(02.4)$ & $4(0.8)$ & 33.3 \\
\hline$>5-10$ & $168(33.6)$ & $83(16.6)$ & $251(50.2)$ & $101(20.2)$ & 40.2 \\
\hline$>10-15$ & $120(24.0)$ & $51(10.2)$ & $171(34.2)$ & $56(11.2)$ & 32.7 \\
\hline$>15-20$ & $33(6.6)$ & $18(3.6)$ & $51(10.2)$ & $16(03.2)$ & 31.4 \\
\hline$>20$ & $11(2.2)$ & $4(0.8)$ & $15(03.0)$ & $8(01.6)$ & 53.3 \\
\hline Total & $\mathbf{3 4 0 ( 6 8 )}$ & $\mathbf{1 6 0}(\mathbf{3 2})$ & $\mathbf{5 0 0 ( 1 0 0 )}$ & $\mathbf{1 8 5 ( 3 7 . 0 )}$ & $\mathbf{3 7 . 0}$ \\
\hline
\end{tabular}

(Number in the parenthesis indicates percentage)

Study showed the distribution of different STHs with their prevalence where AL $63.8 \%$ (118/185), TT 37.3\% (69/185), EV 8.1\% (15/185), AD 7.5\% (14/185), and mixed infection was $15.1 \%(28 / 185)$.

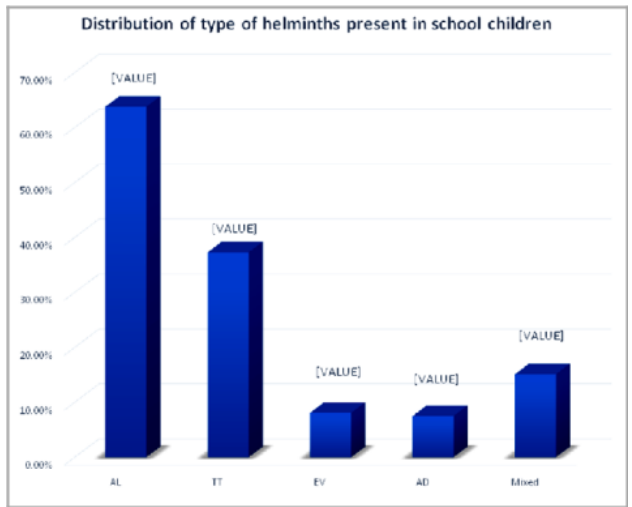

Fig: Bar diagram of different STHs with their prevalence 
In this study the upper socio-economic class constituted $5.0 \%(25 / 500)$ of the total study population with the prevalence of $20.0 \%$ $(5 / 25)$. The middle socio-economic class constituted $50.0 \%(250 / 500)$ of the total study population with the prevalence of $37.2 \%(93 / 250)$ and the lower socioeconomic class constituted $45.0 \%$ (225/500) of the total study population with the prevalence of $38.6 \%(87 / 225)$.

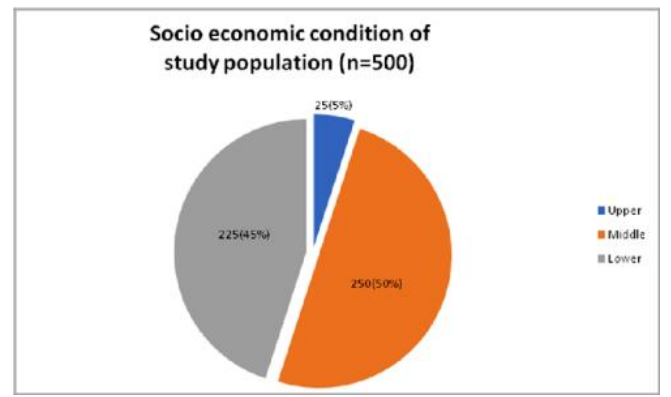

Fig: Socio economic condition of study population.

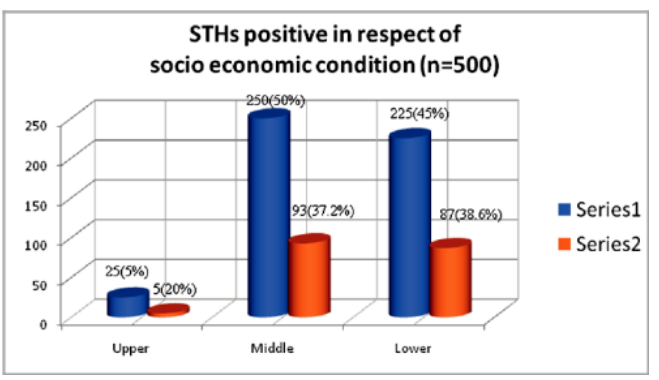

Fig: Socio economic condition of study population.

Study showed the STHs prevalence among the urban and rural study population $(n=500)$, where the urban population constituted $34.0 \%(170 / 500)$ of the total population representing the prevalence $31.2 \%(53 / 170)$. For the rural population constituted $66.0 \%(330 / 500)$ of the total population representing the prevalence $40.0 \%(132 / 330)$.

\section{Discussion}

The burden of parasitic worm infections is considerable, particularly in developing countries. It is acknowledged that parasitic worm infections negatively impact on children's school performance and physical development. In this study, the prevalence was $37 \%$ is noticeable, because of these children are receiving anthelmintics in every 6 months interval under Government National Anthelmintics Program. In this study, three techniques were applied to identify the STHs,

1) Normal saline preparation slide microscopy

2) Lugholes' lodine preparation slide microscopy ${ }^{12}$ and

3) McMaster slide preparation microscopy ${ }^{4}$.

Till today, saline and iodine preparation slide microscopy is the gold standard for detection of STHs, but there may be chance of missing of helminthes detection because of a small amount of specimen is used in this method. This study applied the very recent McMaster technique for identification of STHs; which may have less chance of missing of ova ${ }^{11,18}$.

In the present study, the prevalence of STHs among school children of Mymensingh area was $37.0 \%$, which is similar or very close to the study from home and abroad. In 2009 a STHs study in SouthWest Cameroon included school children showed the prevalence $42.4 \%{ }^{13}$.

In 2009 a STHs study in Holland comprising school children showed the prevalence $47.6 \%{ }^{14}$. In 1990 there was a study in Mymensingh, Bangladesh showed the prevalence of STHs infections $72.2 \%{ }^{14,15}$. Recent study from Dhamrai, Dhaka (IEDCR2011 ) showed the prevalence of STHs $32 \%$.

In the present study, $340 \quad(68.0 \%)$ individuals were male represents $38.0 \%$ prevalence of STHs and 160 (32.0\%) individuals were female representing the prevalence of $35.0 \%$. This is similar to that of other studies done in Asia and South Asian subcontinent where boys and girls ratio was $2: 1^{1,20}$, which well correlated with the present study where boys are more encouraged to go to school and girls are deprived from school 
especially in rural areas. A study in Nigeria (2008) showed, (149/300) 49.7\% individuals were male represents (134/300) $44.7 \%$ positive as parasite and (151/300) 50.3\% individuals were female represents (126/300) $42.0 \%$ positive as parasite ${ }^{1}$. In the present study, the prevalence of STHs was AL $63.8 \%$, TT $37.3 \%$, EV $8.1 \%$, AD $7.5 \%$ and mixed infection $15.1 \%$ A study from India (2004) showed the prevalence of STHs infections for AL 91.0\%, TT 72.0\% and $A D 54.0 \%{ }^{16}$. Another study in Nigeria (2008) showed the prevalence of STHs infections for AL $67.7 \%$, TT $31.3 \%$, AD $45.0 \%$ and SS being the lowest $18.0 \%^{1}$. These study results were compatible with the present study.

In this study, the prevalence in different age group were, $33.3 \%$ in $1-5$ years of age, $40.2 \%$ in $>5-10$ years, $32.7 \%$ in $>10-15$ years, $31.4 \%$ in $>15-20$ years and $53.3 \%$ in $>20$ years of age. The highest prevalence in adult age group of $>20$ years, probably they are detached from national deworming program or may be due to involve in ground work. The most focal age group was $>5-10$ years and $>10-15$ years of age. These two age groups of Children were more susceptible to STHs infection because, they spend more time in ground for playing in bare foot, lack of personal hygiene maintenance, open field defecation in villagers. A study in Zanzibar, Africa (2007) showed the selected age group from 3 to 19 years and their overall prevalence was (166/336) $49.4 \%{ }^{14}$.

The study also found the STHs prevalence in respect of socio-economic condition of the study population, where upper socioeconomic class found $20.0 \%(5 / 25)$, middle socio-economic class found $37.2 \%$ (93/250) and the lower socio-economic class found $38.6 \%(87 / 225)$ STHs prevalence. It was observed that the highest prevalence was among the lower socio-economic group followed by the middle and upper group. Worm transmission is enhanced by poor socio-economic conditions, deficiencies in sanitary facilities, improper disposal of human faces, insufficient supplies of potable water, poor personal hygiene, substandard housing and lack of education ${ }^{17}$.

The present study showed the STHs prevalence was high in rural area $132(40.0 \%)$ then in urban area $53(31.2 \%)$. This indicates parasitic distribution is not homogeneous and varies in relation to geographical areas, especially high in the plantation sector ${ }^{6}$. The high incidence of STHs in rural area highlights the poor sanitation facility resulting in open-air defecation, which results in helminthes egg contamination with soil.

Analyzing the findings of the present study, the prevalence of Soil Transmitted Helminthes (STHs) was found to very high and alarming. For this health education for school children should be actively considered.

Acknowledgement: We gratefully acknowledge Professor Jozef Vercruysse, Professor Edwin Claerebout and Dr Bruno Levecke of Ghent University, Belzium 11 for providing us equipment and technical assistance.

\section{References:}

1. Ibidapo C.A. and O. Okwa, The prevalence and intensity of soil transmitted helminths in a rural community, lagos suburb, south West Nigeria. Int. J. Agri. Biol., 10: 2008, pp.89-92.

2. Hossain MA, Shamsuzzaman AKM, Musa AKM, Khan MAH, Medical Parasitology - basic \& Clinical 2th ed (revised), 2011.

3. Bundy DA, Hall A, Medley GF and Savioli L, evaluating measures to control intestinal parasitic infections; World Health Stat Q45, 1992, pp.168179.

4. Crompton DW, Stephenson LS, Hookworm infection, nutritional status, and productivity. In: Schad GA, Warren KS, eds. Hookworm disease: current status and new directions; London: Taylor and Frances, 1990: pp1990, 231-64.

5. WHO, Deworming for health and development. Report of the third global meeting of the partners for parasitic control. WHO/CDS/CPE/PVC/2005.14, World Health Organisation, Geneva. 2005. 
6. Bethony J, Brooker S, Albonico M, Geiger SM, Loukas A, Diemert D, Hotez PJ, Soil transmitted helminth infections; ascariasis, trichuriasis, and hookworm; Lancet 367, 2006, pp.1521-1532.

7. Hotez PJ, Brooker S, Bethony JM, Bottazzi ME, Loukas A, Xiao S, Hookworm infection; N Engl J Med; 351: 2004, pp.799-807.

8. Gunawardena K, Kumarendran B, Ebenezer R, Gunasingha MS, Pathmeswaran A, SoilTransmitted Helminthes Infections among Plantation Sector Schoolchildren in Sri Lanka: Prevalence after Ten Years of Preventive Chemotherapy; PLoS Negl Trop Dis 5(9): e1341. 2011.

9. Chowdhury $A B$ and Schad GA, Ancylostoma ceylanicum: a parasite of man in Calcutta and environs; Am J Trop Med Hyg 21, 1972, pp.300301.

10. Hussain $T$, Hossain MA, Prevalence of intestinal parasites in the context of socioeconomic status in the rural community, 4(3), pp.105-9.

11. Vercruysse J, Behnke JM, Albonico M, Ame SM, Angebault $C$, Assessment of the anthelmintic efficacy of albendazole in school children in seven countries where soil-transmitted healminths are endemic; PloS Negl Trop Dis 5: e948. 2011.

12. Sarkar NR, Anwar KS, Biswas KB, Mannan MA, Effect of deworming on nutritional status of ascaris infested slum children of Dhaka, Bangladesh. Indian pediatrics 39: 2002, pp.1021-1026.

13. Nkengazong L, Njiokou F, Wanji S, Teukeng F, Enyong $P$, Asonganyi $T$, Prevalence of soil transmitted helminths and impact of Albendazole on parasitic indices in Kotto Barombi and Marumba II villages (South-West Cameroon), African Journal of Environmental Science and Technology Vol. 4(3), 2010, pp. 115-121.

14. Strongyloides stercoralis, among children in Zanzibar. Geospatial Health 3(1), 2008, pp. 4756.

15. Hall A, Nahar Q, Albendazole and infections with Ascaris lumbricoides and Trichuris trichiura in children in Bangladesh; Transactions of the Royal Society of Tropical Medicine and Hygiene 88: 1994, pp.110-112.
16. Traub RJ, Robertson ID, Irwin PJ, Mencke $N$ and Thompson RC, Canine gastrointestinal parasitic zoonoses in India. Trends Parasitol 21, 2005, pp.42-8.

17. Albonico M, Cromptom DW, Savioli L, Control strategies for human intestinal nematode infection; Adv. Parasitol; 42: 1999, pp.277-341.

18. Chalex Corporation 5004-228th Ave SE, Issaquah, WA. USA 98029 http://www.vetslides.com.

19. Rousham EK and Mascie-Taylor CGN, An 18-month study of the effect of periodic anthelmintics treatment on the groweighth and nutritional status of pre-school children in Bangladesh; Department of Biological Anthropology, University of Cambridge, UK Vol. 21, No. 4, 1994, pp.315-324.

20. Khatun M, Naher A, Prevalence of STH infections among Bangladeshi males seeking job abroad, Mymensingh; Med J 2006 Jul; 15(2): pp.159-162. 